\title{
ENERGY AUDIT OF WATER NETWORKS
}

\author{
Enrique Cabrera (member ASCE) ${ }^{1}$, Miguel A. Pardo ${ }^{2}$, Ricardo Cobacho ${ }^{3}$ and \\ Enrique Cabrera $\mathrm{Jr}^{4}$.
}

${ }^{1}$ Professor, ITA, Universidad Politécnica de Valencia, Camino de Vera s/n. 46022, Valencia, Spain. Email: ecabrera@ita.upv.es

${ }^{2}$ MSc, PhD student, ITA, Universidad Politécnica de Valencia, Camino de Vera s/n. 46022, Valencia, Spain. Email: miparpi@ita.upv.es.

${ }^{3}$ Assistant Professor, ITA, Universidad Politécnica de Valencia, Camino de Vera s/n. 46022, Valencia, Spain. Email: rcobacho@ita.upv.es

${ }^{3}$ Associate Professor, ITA, Universidad Politécnica de Valencia, Camino de Vera s/n. 46022, Valencia, Spain. Email: qcabrera@ita.upv.es

\section{ABSTRACT}

This paper presents the energy audit of a water network, which is obtained from the energy equation in integral form, and its time integration extended over a given period (day, month or year). The analysis allows accounting for all the energy in the system, showing that the energy balance is maintained. This balance allows can be used to obtain performance indicators to assess the system from the energetic point of view. From these indicators, it is possible to identify the improvement actions that will make the system more efficient. This energy audit requires a previous water balance and the mathematical model of the network, both of which are necessary to know the energy flows through the system's boundaries.

Keywords: water, energy, audit, efficiency. 


\section{INTRODUCTION}

Until recently, energy savings in the water industry were an operational issue, a pump efficiency matter, a process improvement or simply a management efficiency target (Lingireddy and Wood, 1998). However, due to the periodic energy crisis and the need to reduce greenhouse emissions, there is an increasing motivation to minimize energy requirements in sustainable water use (USDE, 2006). In any case, it is understandable that the degree of concern with a water utility in terms of energy efficiency will depend on the circumstances of the system. If water is obtained from a desalination plant, the required energy before coming into the system is at least $3.5 \mathrm{kWh} / \mathrm{m}^{3}$ (NRC, 2008), and the sensitivity to energy-related issues will thus be high. However, if the water source is natural and has high quality and no treatment costs, energy issues will become secondary.

The present work will analyze in detail the distribution phase in water networks. Until now the analyses performed have consisted of dividing the energy paid $(\mathrm{kWh})$, called hereafter shaft energy, by the volume of water delivered to users $\left(\mathrm{m}^{3}\right)$. This ratio provides for this phase a global estimation of the energy costs per volume, a value that in California ranges from 0.18 to $0.32 \mathrm{kWh} / \mathrm{m}^{3}(\mathrm{CEC}, 2005)$. The example provided in this paper will show that such a range, pending more accurate data, is a valid reference. However, it is a global indicator and does not provide information about how that energy is used along the distribution process, which is the final objective of the energy audit presented here. 
Pelli and Hitz (2000) establish the water-energy relationship in a system in an integral manner and propose two indicators: the infrastructure indicator and the quality indicator. This is an interesting practical approach that combines elements external to the network (such as the efficiency of pumps) but ignores the energy dissipated in friction losses (which depends not only on the consumed flow rate but also on the leakage level). This issue has already been considered by other authors, such as Colombo and Karney (2002), although their analysis does not include the whole network and, when it does, the analysis is particularized for a specific system (Colombo and Karney, 2005).

This paper originates in the study of the energy equation and presents a complete audit of the distribution system contained within a control volume (which may be either the full network or a district metering area). In order to apply Reynolds's transport equation to energy, the different flow terms at all boundaries need to be known. Therefore, a water audit and a calibrated model are required. In other words, the hydraulic problem must first be solved. Since water is incompressible, the mechanical and thermal equations are not coupled (White, 1974), and the energy problem can be solved after the hydraulic one. It must also be noted that the selected control volume will not include pumps. The hydraulic power that the pumps deliver is an external contribution, and their efficiency thus needs to be evaluated independently from the energy audit presented here. This is not the case of regulation valves, which, where present, should be considered part of the system, as they are within the control volume boundaries and influence the problem by increasing friction losses. 
The most relevant novelty of the energy balance presented here is the assessment of the final uses of the energy injected to the system and, specifically, to the energy loss associated with leakage. Such an energy loss results from two different terms: one associated with the water leaking out of the network and another one related to the energy dissipated in friction losses due to the additional flow rate needed to compensate for the leakage while meeting demands. Performance indicators are later used to characterize the whole energy balance, allowing the assessment of the energy efficiency of the network as well as the influence of the energy losses in the optimum pipe renovation period (through a cost-benefit analysis).

The global balances presented to date (Todini, 2000) do not explicitly assess the energy losses associated with leakage. In the current climate change scenario, the need to clearly establish the water-energy relationship justifies this work.

\section{GENERAL APPROACH TO THE PROBLEM}

The integral energy equation can be applied to a control volume with known amounts of water and energy flowing through its boundaries. This implies solving the water balance and the mathematical model of a system contained within a control volume defined at will. Its boundaries define which elements are external (contributing to the energy flow) or internal (storing or dissipating energy). To illustrate the difference between internal and external elements, the example here presented includes both types of elements, an external reservoir and an internal regulation tank. The pumps are external elements, providing shaft work, while service connections and leaks represent the exit control surface of the system. The mathematical model is necessary to quantify the energy flows (inherent to water flows) through the 
boundaries. Figure 1 represents the control volume and the incoming and outgoing flows of energy.

\section{Control Volume}

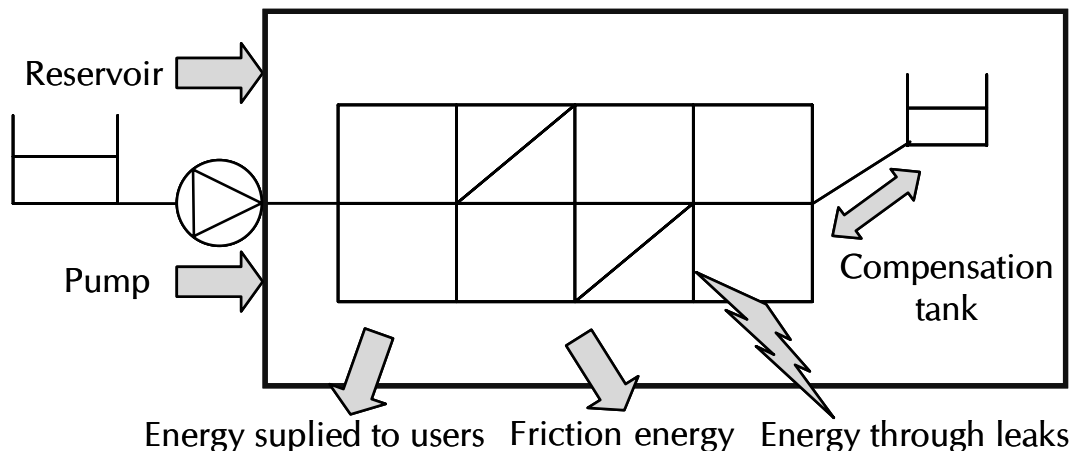

FIGURE 1. WATER NETWORK AS A CONTROL VOLUME WITH THE TERMS OF THE ENERGY BALANCE

By applying the energy equation (which is in fact a power balance) in its most general form to the control volume, Equation (1) is obtained:

$\frac{d E}{d t}=\frac{\partial Q}{\partial t}+\frac{\partial W}{\partial t}=\frac{\partial}{\partial t} \iiint_{C V} e \rho d \forall+\iint_{C S} e \rho(\vec{V} \cdot d \vec{A})$

where $d E / d t$ represents the energy exchange per time unit (sum of the heat exchange, $\partial Q / \partial t$, and the work, $\partial W / \partial t$ ), e represents the total energy per mass unit and $\rho$ represents the fluid density. Developing the unit energy term, Equation (2), which is better suited to our application, can be obtained:

$\frac{\partial Q}{\partial t}+\frac{\partial W_{\text {shaft }}}{\partial t}=\frac{\partial}{\partial t} \iiint_{C V}\left(g z+u+\frac{v^{2}}{2}\right) \rho d \forall+\iint_{C S}\left(\frac{P}{\rho}+g z+u+\frac{v^{2}}{2}\right) \rho(\nabla \cdot d \vec{A})$

Equation 2 can be simplified, given the following assumptions: 
1. Water is incompressible and thus $\rho$ constant.

2. The heat flow through the boundaries is zero $(\partial Q / \partial t=0)$, a reasonable hypothesis for this application. In fact, this is a very complex problem under research (Burch and Christensen, 2007) but it does not affect the final result of the audit. With no heat transfer, friction will slightly increase the temperature of the flowing water.

3. The shaft work, $W_{\text {shaft }}$, is supplied by pumps $\left(\partial W_{\text {shaft }} / \partial t=\sum_{i}^{n_{P}} \chi_{P_{i}} H_{P i}\right)$.

4. The kinetic term $\left(v^{2} / 2\right)$ is neglected as in most network analyses.

5. The performed energy analysis is quasi-static with an extended period integration. In each calculation interval, the energy inside the control volume is constant as far as pipes are concerned, while the energy stored by internal tanks can change.

6. The flow is uniform at the boundaries.

Under these conditions, the energy equation becomes Equation (3):

$$
\sum_{i}^{n_{P}} \mathcal{L}_{P i} H_{P i}=\rho g \frac{\partial}{\partial t} \iiint_{C V} z d \forall+\rho \sum_{\text {Outlets }} Q_{O i}\left[\frac{P_{O i}}{\rho}+g z_{O i}+u_{O i}\right]-\rho \sum_{\text {Inlets }} Q_{l i}\left[\frac{P_{l i}}{\rho}+g z_{l i}+u_{l i}\right]
$$

Typical boundary elements of water networks are reservoirs, tanks and pumps (Rossman, 2000). The energy contribution of the reservoirs, which are external to the system, depends on their head. From the audit's point of view, it is a "natural" energy compared to the "artificial" energy provided by pumps (shaft work). A tank's contribution is also natural, although its elevation is variable with time. As for the energy flows exiting through the nodes, the energy is reflected in the piezometric head. For a generic outlet, the (demand) node (i) is $H_{O i}=P_{O i} / \gamma+z_{O i}$. This value is dependent on the system's reference for elevations. The location of the origin influences the 
final value of the energy indicators. It is advisable to use as the origin of the reference system, $\mathrm{z}=0$, the lowest node of the system.

From the previous considerations, for a system fed from $n_{N}$ reservoirs (constant head) supplying $n$ network outlet nodes, with $n_{P}$ pumping stations providing energy to the system, and with $n_{C}$ compensation tanks, Equation (4) is obtained:

$$
P_{0}=\sum_{i}^{n_{N}} \chi_{N_{N i}} H_{N i}+\sum_{i}^{n_{P}} \chi_{Q_{P i}} H_{P i}=\sum_{i}^{n} \chi_{O i} H_{O i}+\rho\left[\sum_{i}^{n} Q_{O i} u_{O i}-\sum_{i}^{n_{N}} Q_{N i} u_{N i}\right]+\gamma \frac{\partial}{\partial t} \iiint_{V C} z d \forall
$$

The preceding power balance, which refers to the whole system, is similar to the energy balance in Bernoulli's equation, as applied to the ends of a pipe:

- The "natural" power supplied provided by reservoirs and tanks is $P_{N}=\sum_{i}^{n_{N}} \gamma_{N i} H_{N i}$.

- The "artificial" power provided by pumps is $P_{P}=\sum_{i}^{n_{P}} \gamma_{Q i} H_{P i}$.

- The total power supplied, $P_{0}$, comprises both.

- The term $\sum_{i}^{n} \mathcal{Y}_{O i} H_{O i}$ is the exit power through the network outlet nodes, the sum of the power delivered to users (useful power $P_{U}$ ) and the power losses resulting from leakage $\left(P_{L}\right)$.

- The term $\rho\left[\sum_{i}^{n} Q_{O i} u_{O i}-\sum_{i}^{n_{N}} Q_{N i} u_{N i}\right]$ is the variation of the internal energy of water with time. With no heat exchange, the increase of internal energy with time is equal to friction losses $\left(P_{F}\right)$. 
- The term $\gamma \frac{\partial}{\partial t} \iiint_{C V} z d \forall=\sum_{i}^{n_{C}} \pm P_{C i}= \pm P_{C}$ is the change with time (negative or positive) of the potential energy in the $n_{C}$ tanks belonging the system.

Equation (4) can be expressed in a more compact manner as Equation (5):

$P_{N}+P_{P}=P_{U}+P_{L}+P_{F} \pm P_{C}$

This equation states that the power supplied to the network is equal to the power delivered to the users plus the power losses (leakage and mechanical friction), a balance finally adjusted by the compensation term, provided by the tank inside the system. This compensation term becomes less relevant as the integration period increases. The new audit also allows separating the internal power (Todini, 2000) in its two terms $\left(\mathrm{P}_{\mathrm{L}}\right.$ and $\left.\mathrm{P}_{\mathrm{F}}\right)$ while also considering $\mathrm{P}_{\mathrm{C}}$.

\section{EXTENDED PERIOD INTEGRATION OF THE ENERGY EQUATION}

Equation (5) can be integrated through time in a process analogous to the one followed to simulate the hydraulic behavior of a water network with time. The integration converts the power terms into energy terms. The adopted notation is shown in Figure 2.

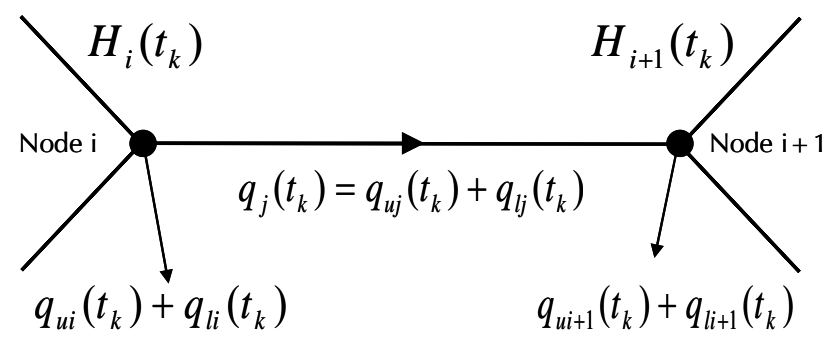

FIGURE 2. NOTATION USED TO INTEGRATE THE ENERGY EQUATION

$q_{u i}\left(t_{k}\right), q_{l i}\left(t_{k}\right)$ supplied and leakage flow rate delivered in node $\mathrm{i}$ at time $t_{k}$.

$q_{u j}\left(t_{k}\right), q_{l j}\left(t_{k}\right)$ supplied and leakage flow rate circulating in line $\mathrm{j}$ at time $t_{k}$.

$H_{i}\left(t_{k}\right)$, piezometric head in node $i$ at time $t_{k}$. 
The energies resulting from the integration of Equation (5) for a simulation period totaling time $t_{p}$ are listed in Table 1.

TABLE 1. ENERGIES INVOLVED IN THE AUDIT

\begin{tabular}{lc}
\hline Energy & Notation \\
\hline Natural energy (supplied by external sources) & $E_{N}\left(t_{p}\right)$ \\
Shaft energy (supplied by pumps) & $E_{P}\left(t_{p}\right)$ \\
Useful energy delivered to users & $E_{U}\left(t_{p}\right)$ \\
Leakage energy losses & $E_{L}\left(t_{p}\right)$ \\
Friction energy losses & $E_{F}\left(t_{p}\right)$ \\
Compensation energy (associated with internal system tanks) & $E_{C}\left(t_{p}\right)$ \\
\hline
\end{tabular}

The difference between natural and shaft energy makes plenty of sense. When water comes into the distribution system, it has its own previously acquired energy footprint (take for instance the transport and treatment energy consumption in $\mathrm{kWh} / \mathrm{m}^{3}$ ). In the distribution phase, the natural energy does not modify this footprint, while the shaft energy is included as a new term.

\section{Input energy supplied by the reservoir}

The external energy, supplied by reservoirs or external tanks, is $E_{N}\left(t_{p}\right)=\gamma \cdot \sum_{i=1}^{i=n_{N}}\left(\sum_{t_{k}=t_{1}}^{t_{k}=t_{p}} Q_{N i}\left(t_{k}\right) \cdot H_{N i}\left(t_{k}\right)\right) \cdot \Delta t$, where $\gamma$ is the specific weight of water, $Q_{N}\left(t_{k}\right)$ is the flow rate supplied at the time $t_{k}, H_{N}\left(t_{k}\right)$ is the piezometric head at time $t_{k}$, and $\Delta t$ is the considered time interval of integration. In order to perform the analysis in an extended period, it is necessary to add the different $n_{i}$ intervals included in that period $\left(t_{p}=n_{i} \cdot \Delta t\right)$. 
If the head of the external sources is constant, the same equation can be simplified resulting $\operatorname{in} E_{N}\left(t_{p}\right)=\gamma \cdot \sum_{i=1}^{i=n_{N}} \forall_{N i} \cdot H_{N i}$, with $\forall_{N i}$ being the volume supplied by reservoir $i$ during the whole analysis period and $H_{N i}$ the piezometric head of water in that reservoir. This equation reflects the incoming natural energy into the system.

\section{Energy supplied by pumping stations (shaft work)}

The shaft work supplied by pumps is $E_{P}\left(t_{p}\right)=\gamma \cdot \sum_{i=1}^{i=n_{P}}\left(\sum_{t_{k}=t_{1}}^{t_{k}=t_{p}} Q_{P i}\left(t_{k}\right) \cdot H_{P i}\left(t_{k}\right)\right) \cdot \Delta t$, where $Q_{P i}\left(t_{k}\right)$ is the flow rate pumped by station $i$ at time $t_{k}$ and $H_{P i}\left(t_{k}\right)$ is the head of the pump. This calculation needs to be done for all $n_{P}$ pumping stations that supply shaft work at the different time instants $k$.

\section{Energy supplied to users}

The useful energy delivered to the customers is $E_{U}\left(t_{p}\right)=\gamma \cdot \sum_{i=1}^{i=n}\left(\sum_{t_{k}=t_{1}}^{t_{k}=t_{p}} q_{u i}\left(t_{k}\right) \cdot H_{i}\left(t_{k}\right)\right) \cdot \Delta t$, where the number of demand nodes is $n$.

\section{Outgoing energy through leaks}

Leaks in mathematical models are concentrated in demand nodes and behave as a pressuredriven demand. Although in the audit they appear as lost energy, they are modeled as energy leaving the system, which is formally analogous to the energy delivered to users:

$$
E_{L}\left(t_{p}\right)=\gamma \cdot \sum_{i=1}^{i=n}\left(\sum_{t_{k}=t_{1}}^{t_{k}=t_{p}} q_{l i}\left(t_{k}\right) \cdot H_{i}\left(t_{k}\right)\right) \cdot \Delta t
$$




\section{Friction energy}

The energy dissipated in the system due to friction is $E_{F}\left(t_{p}\right)=\gamma \cdot \sum_{j=1}^{j=n_{L}}\left(\sum_{t_{k}=t_{1}}^{t_{k}=t_{p}}\left(q_{u j}\left(t_{k}\right)+q_{l j}\left(t_{k}\right)\right) \cdot \Delta h_{j}\left(t_{k}\right)\right) \cdot \Delta t$ where $n_{L}$ is the number of lines of the network and $\Delta h_{j}\left(t_{k}\right)$ the friction losses in line $\mathrm{j}$ at time $t_{k}$ (known from the mathematical model of the network).

The flow rate in line $j$, Figure 2 , is $q_{j}\left(t_{k}\right)=q_{u j}\left(t_{k}\right)+q_{l j}\left(t_{k}\right)$. This equation shows that the leaked flow rate (flows through the network before leaking out) generates additional friction losses. The energy audit will determine the value of this additional energy by simulating the network's behavior with and without leaks. Representing a global balance for the whole water distribution network and not divided in lines, the individual values, $q_{u j}\left(t_{k}\right)$ and $q_{l j}\left(t_{k}\right)$ remain unknown, although for this analysis, this fact bears little relevance.

\section{Energy compensation of the downstream tank}

Many networks have a compensation tank to accumulate water during low consumption hours while releasing it in peak hours. These tanks belong to the system. However, the net flow of water and energy in one of these tanks, when integrated through a long enough period, is zero, and so is their contribution to the long-term analysis. During normal operation, with shorter periods, the tanks can be considered mass and energy sources and sinks and must be included in the audit. 
The variation of potential energy stored in tanks of constant section for a given period of time is $\Delta E_{C}\left(t_{p}\right)=\sum_{i=1}^{i=n_{C}}\left(E_{C_{i}}\left(t_{p}\right)-E_{C_{i}}\left(t_{1}\right)\right)=\gamma \cdot \sum_{i=1}^{i=n_{C}}\left(A_{i} \cdot\left(z_{i}{ }^{2}\left(t_{p}\right)-z_{i}^{2}\left(t_{1}\right)\right) / 2\right)$, with $\quad A_{i} \quad$ being the section of compensation tank $i$ and $z_{i}\left(t_{p}\right), z_{i}\left(t_{1}\right)$ the levels of the free surface of water of tank $i$ at the initial and final times. The maximum variation of this energy, $\Delta E_{C \max }$, obviously corresponds to total oscillation between empty and full tanks of the whole system.

\section{GLOBAL ENERGY BALANCE}

The energy balance for a given period is the result of integrating Equation (4) over time (energy results from integrating power with time). These energies (except the compensation term) enter or exit the system or, otherwise, are dissipated. This enables the derivation of Equation (6):

$$
\begin{aligned}
E_{\text {Input }}\left(t_{p}\right) & =E_{N}\left(t_{p}\right)+E_{P}\left(t_{p}\right)= \\
= & E_{U}\left(t_{p}\right)+E_{L}\left(t_{p}\right)+E_{F}\left(t_{p}\right)+\Delta E_{C}\left(t_{p}\right)=E_{\text {Output }}\left(t_{p}\right)+E_{\text {Dissipated }}\left(t_{p}\right)+\Delta E_{\text {Compensation }}\left(t_{p}\right) .
\end{aligned}
$$

Developing the terms results in Equation (7).

$$
\begin{aligned}
\gamma \cdot \sum_{i=1}^{i=n_{N}}\left(\sum_{t_{k}=t_{1}}^{t_{k}=t_{p}} Q_{N i}\left(t_{k}\right) \cdot H_{N i}\left(t_{k}\right)\right) \cdot \Delta t+\gamma \cdot \sum_{i=1}^{i=n_{P}}\left(\sum_{t_{k}=t_{1}}^{t_{k}=t_{p}} Q_{P i}\left(t_{k}\right) \cdot H_{P i}\left(t_{k}\right)\right) \cdot \Delta t= \\
=\gamma \cdot \sum_{i=1}^{i=n}\left(\sum_{t_{k}=t_{1}}^{t_{k}=t_{p}} q_{u i}\left(t_{k}\right) \cdot H_{i}\left(t_{k}\right)\right) \cdot \Delta t+\gamma \cdot \sum_{i=1}^{i=n}\left(\sum_{t_{k}=t_{1}}^{t_{k}=t_{p}} q_{l i}\left(t_{k}\right) \cdot H_{i}\left(t_{k}\right)\right) \cdot \Delta t+ \\
+\gamma \cdot \sum_{j=1}^{j=n_{L}}\left(\sum_{t_{k}=t_{1}}^{t_{k}=t_{p}}\left(q_{u j}\left(t_{k}\right)+q_{l j}\left(t_{k}\right)\right) \cdot \Delta h_{j}\left(t_{k}\right)\right) \cdot \Delta t+\gamma \cdot \sum_{i=1}^{i=n_{C}}\left(A_{i} \cdot\left(z_{i}{ }^{2}\left(t_{p}\right)-z_{i}{ }^{2}\left(t_{1}\right)\right) / 2\right) .
\end{aligned}
$$


The aforementioned compensation term is only relevant in short-term simulations. The threshold value, $t_{p, B}$, separating the short term from the long term is established by imposing that the maximum compensation energy is only a small percentage of the system energy input $\left(E_{\text {lnput }}\right)$. For a $1 \%$ value, this threshold is:

$t_{p, T}($ days $)=\frac{\Delta E_{c, \max }}{\frac{1}{100} \cdot E_{\text {lnput }}(\text { daily })}$

Therefore, if the energy audit is assessed annually, the compensation term may be withdrawn, and Equation (6) becomes Equation (9). Table 2 summarizes a long-term audit:

$E_{\text {Input }}\left(t_{p}\right)=E_{N}\left(t_{p}\right)+E_{P}\left(t_{p}\right)=E_{U}\left(t_{p}\right)+E_{L}\left(t_{p}\right)+E_{F}\left(t_{p}\right)=E_{\text {Output }}\left(t_{p}\right)+E_{\text {Dissipated }}\left(t_{p}\right)$.

TABLE 2. ENERGY BALANCE FOR A DRINKING WATER NETWORK ON THE LONG TERM

\begin{tabular}{|c|c|c|c|}
\hline \multirow{4}{*}{$E_{\text {Input }}\left(t_{p}\right)$} & \multirow{2}{*}{$\begin{array}{c}E_{N}\left(t_{p}\right) \\
\text { (natural input energy) }\end{array}$} & $\begin{array}{c}E_{U}\left(t_{p}\right) \\
\text { (energy delivered to users) }\end{array}$ & \multirow{3}{*}{$E_{\text {Output }}\left(t_{p}\right)$} \\
\hline & & $E_{L}\left(t_{p}\right)$ & \\
\hline & \multirow{2}{*}{$\begin{array}{c}E_{P}\left(t_{p}\right) \\
\text { (shaft input energy) }\end{array}$} & (outgoing energy through leaks) & \\
\hline & & $\begin{array}{l}\qquad E_{F}\left(t_{p}\right) \\
\text { (friction energy) }\end{array}$ & $E_{\text {Dissipated }}\left(t_{p}\right)$ \\
\hline
\end{tabular}




\section{BASIC ENERGY INDICATORS}

Energy indicators have traditionally been expressed in $\mathrm{kWh} / \mathrm{m}^{3}$ as the ratio between the billed shaft work and the metered volume. The indicators proposed here provide an overall and intuitive assessment of the system and have sense mostly in the long term. The piezometric heads are set to the lowest node, which is taken as the $\mathrm{z}=0$ reference, a criterion that affects the values of the indicators (as all the analysis is carried out by means of piezometric heads) deeming impossible the comparison with other systems.

\section{Context information}

Each system is, from an energetic point of view, different. The network can be flat or hilly, and it may or may not require intermediate pumping stations. It is obvious that a system supplied from a source located at a higher point represents an ideal situation, as it needs no pumping at all. The opposite case is a system supplied from groundwater where every cubic meter requires a significant amount of energy before it reaches users. The difference in context between these two situations is covered by the first "context indicator" $C_{1}$ (formally, it cannot be considered context information - see the definition in Alegre et al. 2006 - as it may slightly change depending on leakage or friction, but in our experience, it is a constant enough value and provides valuable context data to compare utilities). $c_{1}$ (Table 3) shows which portion of the energy delivered to the system is natural and ranges from 0 to 1 , with the maximum being reached when all the injected energy is gravitational, being provided by a high water source. 
The second context information item $c_{2}$, Table 3, takes into account how demanding from an energy point of view the network is. As the ratio between the minimum useful energy $E_{\min , u s e f u l}$ defined in each node from the minimum required head $\left(h_{\text {Min }, i}=z_{i}+P_{\text {Min }} / \gamma\right)$ and a theoretical minimum required energy (for a flat, leak free and frictionless network) $E_{\min , f l a t}$. Since this ideal network corresponds to a flat layout with all nodes located at the same maximum height $\mathrm{z}_{\max }$, the best possible value of $C_{2}$ is one.

TABLE 3. CONTEXT INFORMATION

\begin{tabular}{|c|c|}
\hline $\begin{array}{c}C_{1} \\
\text { Energy nature }\end{array}$ & $C_{2}$ \\
\hline$C_{1}=\frac{E_{N}\left(t_{p}\right)}{E_{\text {Input }}\left(t_{p}\right)}$ & $C_{2}=\frac{E_{\min , \text { useful }}}{E_{\min , f l a t}}=\frac{\gamma \cdot \sum_{k=t_{1}}^{k=t_{p}} \sum_{i=1}^{n} q_{u i}\left(t_{k}\right) \cdot\left(h_{\text {Min }}\right)_{i} \cdot \Delta t}{\gamma \cdot \frac{P_{\min }}{\gamma} \cdot \forall_{U}\left(t_{p}\right)}=\frac{\sum_{i=1}^{n} \theta_{u, i}\left(t_{p}\right) \cdot h_{\text {min }, i}}{\frac{P_{\min }}{\gamma} \cdot \forall_{U}\left(t_{p}\right)}$ \\
\hline
\end{tabular}

\section{Efficiency indicators}

As defined in the IWA manual of performance indicators (Alegre et al., 2006) the context information items provided above are useful for characterizing the system. However, they cannot be changed by management decisions and thus should not be used to measure how well the system is managed. In order to perform such an analysis, five performance indicators are proposed (Table 4): 
TABLE 4. ENERGY EFFICIENCY INDICATORS

\begin{tabular}{|c|c|c|}
\hline $\begin{array}{c}l_{1} \\
\text { Excess of supplied energy }\end{array}$ & $\begin{array}{c}I_{2} \\
\text { Network energy efficiency }\end{array}$ & $\begin{array}{l}\qquad I_{3} \\
\text { Energy dissipated through friction }\end{array}$ \\
\hline$I_{1}=\frac{E_{\text {input }}\left(t_{p}\right)}{\sum_{i=1}^{n} \theta_{u, i}\left(t_{p}\right) \cdot h_{\min , i}}$ & $I_{2}=\frac{E_{U}\left(t_{p}\right)}{E_{\text {Input }}\left(t_{p}\right)}$ & $I_{3}=\frac{E_{F}\left(t_{p}\right)}{E_{\text {Input }}\left(t_{p}\right)}$ \\
\hline \multicolumn{2}{|c|}{$\begin{array}{c}I_{4} \\
\text { Leakage Energy }\end{array}$} & $\begin{array}{c}I_{5} \\
\text { Standards compliance }\end{array}$ \\
\hline \multicolumn{2}{|c|}{$\frac{E_{L}\left(t_{p}\right)+E_{F}\left(t_{p}\right)-E_{F}^{\prime}\left(t_{p}\right)}{E_{\text {Input }}\left(t_{p}\right)}$} & $I_{5}=\frac{E_{U}\left(t_{p}\right)}{\gamma \cdot \sum_{i=1}^{n} \theta_{u, i}\left(t_{p}\right) \cdot h_{\min , i}}$ \\
\hline
\end{tabular}

- The first indicator, $l_{1}$, is the ratio between the real energy entering the system and the minimum useful energy.

- $I_{2}$, is a measure of the efficiency of the use of the energy injected to the system (which fraction of the total energy input is useful).

- $I_{3}$ represents the hydraulic capacity of the network. A higher value indicates lower efficiency. Although this can be brought to values very close to zero, eliminating friction losses implies a very costly design. Target values depend on a balance between investment and running costs.

- The fourth indicator, $I_{4}$, measures the energy loss due to leakage, which results from the sum of energy loss through leaked water $E_{L}\left(t_{p}\right)$ and the additional energy required to overcome friction with the increased flow rate needed to overcome leakage (difference between the actual energy dissipated in friction losses $E_{F}\left(t_{p}\right)$ and the value of friction losses in a leak-free network, $\left.E_{F}^{\prime}\left(t_{p}\right)\right)$. 
- Finally, $I_{5}$, is the direct ratio between the energy delivered to users and the minimum required useful energy. It is a network-level indicator that averages the overall condition of the system but may leave sector performance unnoticed (the average condition may be good while some sectors are performing poorly). At a first glance, $I_{5}$ can be interpreted as follows:

$I_{5}<1$ shows that average pressure levels are insufficient and below standards. The minimum value for a given network appears when water is delivered to users by means of underground tanks located in users' households. The supply pressure would then be atmospheric and the numerator of $I_{5}$ equal to: $\gamma \cdot \sum_{i=1}^{i=n}\left(\sum_{t_{k}=t_{1}}^{t_{k}=t_{p}} q_{u i}\left(t_{k}\right) \cdot z_{i}\right) \cdot \Delta t$

$I_{5}>1$ is the most common case. The pressure is kept above the service standards. A value closer to 1 indicates greater efficiency in meeting them. On the other hand, such an excess of potentially recoverable energy depends mainly on the minimum excess pressure value $\Delta \mathrm{p}_{\min }$ (the minimum value for all nodes and all simulation intervals of the difference between the real pressure and the minimum allowable value $\left.p_{\text {service }}-p_{\text {min }}\right)$. However, the actual possibility of recovering such energy greatly depends of the characteristics and operation of the network. Another possibility is that even when $I_{5}>1$, some node may not satisfy the pressure standard, in which case $\Delta \mathrm{p}_{\min }$ would be negative. 


\section{NUMERICAL EXAMPLE}

To illustrate both the energy audit and the use of the proposed indicators, a numerical example is presented. As water balances are usually assessed in coincidence with meter-reading periods (month, trimester or year) usually the audits will be assessed over the long term.

\section{Basic data}

Figure 3 shows the network layout while Table 5 shows the node and line data. Node 33, which is the lowest point in the network, becomes the origin for elevations and all other values are given in reference to this elevation. The simulations were carried out using the EPANET 2.0 toolkit.

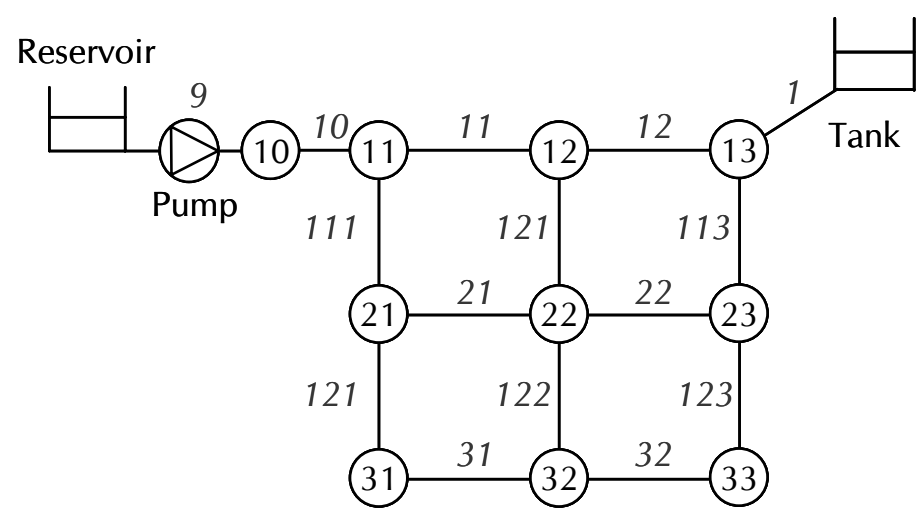

Figure 3. General LAYOUt OF THE NETWORK 
TABLE 5. LINE AND NODE DATA

\begin{tabular}{ccccccc}
\hline Line & Length $(\mathbf{k m})$ & $\begin{array}{c}\text { Diameter } \\
(\mathbf{m m})\end{array}$ & Node & $\begin{array}{c}\text { Base } \\
\text { demand } \\
\mathbf{( 1 / \mathbf { s } )}\end{array}$ & $\begin{array}{c}\text { Elevation } \\
\mathbf{( m )}\end{array}$ & $\begin{array}{c}\text { Emitter } \\
\mathbf{c o e f f i c i e n t} \\
\left(\mathbf{m}^{3-\alpha} / \mathbf{s}\right)\end{array}$ \\
\hline 10 & 2 & 400 & Node 10 & 0 & 5.8 & 0.002611285 \\
11 & 2 & 300 & Node 11 & 5 & 5.8 & 0.010445142 \\
12 & 2 & 350 & Node 12 & 5 & 4 & 0.010445142 \\
21 & 2 & 200 & Node 13 & 3 & 2 & 0.010445142 \\
22 & 2 & 200 & Node 21 & 5 & 4 & 0.013056427 \\
31 & 2 & 200 & Node 22 & 6.5 & 2 & 0.015667712 \\
111 & 4 & 200 & Node 23 & 5 & 0 & 0.013056427 \\
112 & 4 & 250 & Node 31 & 3 & 4 & 0.007833856 \\
113 & 4 & 300 & Node 32 & 3 & 5 & 0.010445142 \\
121 & 4 & 200 & Node 33 & 3 & 0 & 0.007833856 \\
122 & 4 & 200 & Reservoir & - & 25 & - \\
123 & 4 & 200 & Tank & - & 32 & - \\
32 & 2 & 200 & & & & \\
1 & 2 & 400 & & & & \\
\hline
\end{tabular}

TABLE 6. HOURLY COEFFICIENTS OF WATER DEMAND MODULATION

\begin{tabular}{lllllllllllll}
\hline Time & $\mathbf{1}$ & $\mathbf{2}$ & $\mathbf{3}$ & $\mathbf{4}$ & $\mathbf{5}$ & $\mathbf{6}$ & $\mathbf{7}$ & $\mathbf{8}$ & $\mathbf{9}$ & $\mathbf{1 0}$ & $\mathbf{1 1}$ & $\mathbf{1 2}$ \\
Coefficient & 0.6 & 0.5 & 0.45 & 0.45 & 0.5 & 0.5 & 0.9 & 1.3 & 1.4 & 1.1 & 1.5 & 1.4 \\
\hline Time & $\mathbf{1 3}$ & $\mathbf{1 4}$ & $\mathbf{1 5}$ & $\mathbf{1 6}$ & $\mathbf{1 7}$ & $\mathbf{1 8}$ & $\mathbf{1 9}$ & $\mathbf{2 0}$ & $\mathbf{2 1}$ & $\mathbf{2 2}$ & $\mathbf{2 3}$ & $\mathbf{2 4}$ \\
Coefficient & 1.4 & 1.45 & 1.45 & 1.3 & 1.2 & 1.2 & 1.1 & 1.1 & 1.2 & 1.1 & 0.9 & 0.7 \\
\hline
\end{tabular}

The pipe roughness is $0.1 \mathrm{~mm}$. The diameter of the compensation tank is $20 \mathrm{~m}$, and its level oscillates between $2.5 \mathrm{~m}$ (initial value for the simulation) and $7 \mathrm{~m}$ (maximum value). The minimum node pressure $(22 \mathrm{mcw})$ is maintained by a pump (characteristic curve: $\left.H=93.33-0.003646 \cdot Q^{2}\right)$. The pump starts and stops when the water level reaches the limits in the tank. The two simulation periods correspond to one day for the short term and one year for the long term, a value clearly above the "long-term" threshold ( in our example, as shown later, $t_{p, T}=16$ days). 
The initial annual water audit (apparent losses are included in the delivered water) is:

- Injected water: $\forall_{N}\left(t_{p}\right)=1.743 \mathrm{hm}^{3} /$ year.

- Delivered water: $\forall_{U}\left(t_{p}\right)=1.214 \mathrm{hm}^{3} /$ year.

- Real losses: $\forall_{L}\left(t_{p}\right)=0.529 \mathrm{hm}^{3} /$ year.

Both the total user demand and the hourly modulation coefficients are constant along the year. Table 6.

The leakage flow rates at the nodes are determined supposing that they are proportional both to the pressure in the node (pressure driven demand) and to the length of the pipes linked to it (uniform distribution). Additionally, the continuity equation needs to be fulfilled (and therefore the sum of all volumes leaked through the nodes must be in accordance with the water audit results). Each nodal leak is characterized through the corresponding emitter, which is adjusted by successive approximations in a quick convergence method described in Almandoz et al. (2005). The characteristics of the emitters follow the EPANET model $q_{l i}\left(t_{k}\right)=C_{E, i} \cdot\left[\Delta H_{i}\left(t_{k}\right)\right]^{\alpha}$ (Rossman, 2000), where $c_{E, i}\left(\mathrm{~m}^{3-\alpha} / \mathrm{s}\right)$ is the coefficient assigned to each node, $\Delta H_{i}\left(t_{k}\right)(\mathrm{m})$ the pressure variation through the leak and $\alpha=1.2$ the emitter exponent that models the characteristics of the pipe material. The resulting emitters' coefficients are also depicted in Table 5. 


\section{Results}

Table 7 shows the results of the four analyzed cases. They correspond to daily and annual simulations for both an ideal network (no leaks) and a real network. While the first period can be considered a short one, the second qualifies as a long-term simulation, with a period much longer than the $t_{p, T}=16$ days required by Equation (8), as the input energy is $E_{\text {input }}\left(t_{p}\right)=1364.41$ $\mathrm{kWh} /$ day and the maximum variation in the compensation tank is $\Delta E_{c, \max }=218.62 \mathrm{kWh}$. The hydraulic time step used to calculate the simulations is 1 minute for the short-term simulations and 15 minutes for the long-term ones.

TABLE 7. ENERGY BALANCE (ALL CASES PRESENTED)

\begin{tabular}{|c|c|c|c|c|c|}
\hline \multirow{2}{*}{} & \multicolumn{2}{c|}{ Real network } & \multicolumn{2}{c|}{ Ideal network (no leaks) } \\
\cline { 3 - 6 } Energy & $\begin{array}{c}\text { Short Term } \\
t_{p}<t_{p, T} \\
(\mathrm{kWh} / \text { day) }\end{array}$ & $\begin{array}{c}\text { Long Term } \\
t_{p}>t_{p, T} \\
(\mathrm{MWh} / \text { year) }\end{array}$ & $\begin{array}{c}\text { Short Term } \\
t_{p}<t_{p, T} \\
(\mathrm{kWh} / \mathrm{day})\end{array}$ & $\begin{array}{c}\text { Long Term } \\
t_{p}>t_{p, T} \\
(\mathrm{MWh} / \text { year) }\end{array}$ \\
\hline \multirow{2}{*}{$E_{\text {Input }}\left(t_{p}\right)$} & $E_{N}\left(t_{p}\right)$ & $386.66(28.3 \%)$ & $118.75(28.7 \%)$ & $322.52(27.3 \%)$ & $82.79(27.7 \%)$ \\
\hline & $E_{P}\left(t_{p}\right)$ & $977.75(71.7 \%)$ & $294.76(71.3 \%)$ & $857.95(72.7 \%)$ & $215.60(72.3 \%)$ \\
\hline$E_{\text {Output }}\left(t_{p}\right)$ & $E_{U}\left(t_{p}\right)$ & $453.20(33.2 \%)$ & $169.13(40.9 \%)$ & $501.71(42.5 \%)$ & $179.73(60.2 \%)$ \\
& $E_{L}\left(t_{p}\right)$ & $232.67(17.1 \%)$ & $77.53(18.8 \%)$ & $-(0 \%)$ & $-(0 \%)$ \\
\hline$E_{\text {Dissipated }}\left(t_{p}\right)$ & $\Delta E_{C}\left(t_{p}\right)$ & $128.87(9.4 \%)$ & $0.17(0.0 \%)$ & $217.28(18.4 \%)$ & $0.20(0.1 \%)$ \\
\hline
\end{tabular}

The theoretical energies, defined as $E_{\min , u s e f u l}$ and $E_{\min , f l a t}$, are equal to $219.67 \mathrm{kWh} /$ day (80.18 MWh/year) and $199.42 \mathrm{kWh} /$ day $(72.79 \mathrm{MWh} /$ year), values that correspond to an almost flat network. Additionally, the results in Table 7 show that:

- In a leak-free network, there are additional advantages to the obvious energy input savings $(1180.47 \mathrm{kWh} /$ day versus $1364.41 \mathrm{kWh} /$ day $)$. Additionally, the network performance is clearly improved. This is shown by the amount of energy received by 
users (501.71 $\mathrm{kWh} /$ day versus $453.20 \mathrm{kWh} /$ day) with all of the improvement possibilities that come with it. The leak-free system involves a higher value of $I_{5}$, revealing to what extent leakage consumed extra capacity already existing in the system, and that such extra capacity is an opportunity for further improvement in energy performance by reducing pumping output to curtail unnecessary surplus pressure at the delivery points. It also reveals a better situation for future network expansions. Quantifying these improvements delivers the $\Delta$ pmin value, which for a leaking network is 1.05 m.c.w. for the short-term simulation and 0.21 m.c.w. for the long-term one. The values increase to 6.85 m.c.a. and 6.69 m.c.a., respectively, in the case of a leak-free network. These minimum values are registered when the network input point is the compensation tank in node 31 . The partial or total recovery of these energy surpluses requires the optimization of the operating conditions of the network.

- The energy loss associated with leaks (which is lost directly through them) is 232.67 $\mathrm{kWh} /$ day, but the total energy loss is larger when the additional friction losses are considered (the difference between the $549.84 \mathrm{kWh} /$ day and the $461.48 \mathrm{kWh} /$ day of the leak free network). This brings the total daily savings to $321.03 \mathrm{kWh} / \mathrm{day}$ (which represents $27.2 \%$ of the total energy in use).

- If percentages are taken into account, the audit shows that while there is little variation in the input energy, there are great differences when considering the energy delivered to users. The differences observed between the two scenarios are to a great extent due to the significant participation in the short term of the compensation energy in the tank. 
- The energy dissipated in friction losses $E_{F}\left(t_{p}\right)=166.86 \mathrm{MWh} /$ year is equal to the increment in internal energy of $\rho \cdot\left(\sum_{i=1}^{i=n} Q_{O i} u_{O i}-\sum_{i=1}^{i=n_{N}} Q_{N i} u_{N i}\right)=E_{F}\left(t_{p}\right)$ provided that no heat is exchanged. Under these conditions, the water temperature increases by $0.08^{\circ} \mathrm{C}$ on average (being $\rho=1000 \mathrm{~kg} / \mathrm{m}^{3}, C_{p}=4180 \mathrm{~J} / \mathrm{kg} / \mathrm{K}$ and $\Delta u=C_{p} \cdot \Delta T$ ).

\section{Energy assessment of the network with the new indicators}

The aforementioned indicators defined can help to assess, compare and improve the energy efficiency of different networks. They can be calculated with the results of both short-term and long-term energy audits, although short-term analyses may create distortions in the indicators' values.

Utilities often use the shaft energy per volume indicator $\left(\mathrm{kWh} / \mathrm{m}^{3}\right)$, which can be referred to for both injected and consumed volumes. However, when the objective is to assess the energy efficiency, it makes sense to use the delivered volume as a denominator, for it is the ultimate goal of the utility (i.e., to provide users with a certain volume of water). This can clearly be seen when comparing both possibilities in our example. For the ideal network, both volumes are the same, and so are the indicator values $\left(0.17 \mathrm{kWh} / \mathrm{m}^{3}\right)$. In the real network, the values are 0.17 $\mathrm{kWh} / \mathrm{m}^{3}$ when referring to the injected volume and $0.24 \mathrm{kWh} / \mathrm{m}^{3}$ when referring to the delivered volume. It must thus be underlined that if the energy intensity of injected water is calculated, a leaking network would appear to be as energy efficient as a leak-free one $\left(0.17 \mathrm{kWh} / \mathrm{m}^{3}\right.$ in both cases). When the comparison is carried out taking into account the delivered volume, the absence of leaks becomes a clear energy advantage $\left(0.17\right.$ vs. $\left.0.24 \mathrm{kWh} / \mathrm{m}^{3}\right)$. 
Utilities become sensitive to this indicator, as their energy sources are becoming more expensive. Although full gravity-driven systems would not feel the urgency to account for this indicator, as the energy they use appears 'free', within a broader context of resource scarcity, higher water and energy prices, and the pressure any future climate change might place on these, opportunities for recovering existing capacity become more relevant, and the opportunity cost of energy inefficiency more apparent. The possibility of employing micro-turbines to recapture energy in cases where chronic dissipation would otherwise be the norm ought to be entertained when feasible.

Table 8 presents for both scenarios the value of the new energy indicators assessed with the results of annual audits. All of them improve as leaks disappear. In the case of $I_{5}$ this is due to the increase of useful energy delivered to users. Especially remarkable is the improvement of $I_{4}$, although it comes as no surprise, as this indicator is closely related to leakage values.

TABLE 8. ENERGY INDICATORS

\begin{tabular}{cccccccc}
\hline & $C_{1}$ & $C_{2}$ & $I_{1}$ & $I_{2}$ & $I_{3}$ & $I_{4}$ & $I_{5}$ \\
& & & & & & & \\
\hline Real network & 0.28 & 1.10 & 5.16 & 0.41 & 0.40 & 0.30 & 2.11 \\
Ideal network & 0.28 & 1.10 & 3.72 & 0.60 & 0.40 & 0.00 & 2.24 \\
\hline
\end{tabular}

Context information, as expected, is independent of the state of the network (such is the condition to be considered context, Alegre et al. 2006). The first context information item shows that less than $30 \%$ of the injected energy is natural. $c_{2}$. with a value close to 1 , indicates that the network is quite flat.

The first indicator $I_{1}$ shows that the input energy of the network is more than 5 times the minimum amount of energy necessary to supply the service, leaving significant room for improvement. As a matter of fact, when leakage disappears, this indicator is brought down to 
3.72. Additional strategies to improve this indicator could include re-designing the network diameters to reduce friction losses or installing variable-speed pumps to better adjust to pressure requirements.

$I_{2}$ shows which percentage of the energy is delivered to the users ( $41 \%$ in the real network). This leaves $59 \%$ of the energy being lost through either leakage or friction. In a leakage-free scenario, the value reaches $60 \%$ (representing an almost 50\% improvement).

The third indicator shows how much energy is used to overcome friction in pipes. In this case, a value this high $(40 \%)$ indicates that the length of the network is very significant, the diameters are tight, or a combination of both factors. The value is the same for both scenarios, which is understandable in a leak-free situation, as the friction energy is reduced, but so is the input energy. In any case, a value of $40 \%$ is high enough to trigger the substitution of key pipes with larger ones.

Of all the indicators, $I_{4}$ is probably the most innovative one. It shows which fraction of the energy entering the system is lost due to leakage. A deeper analysis could include energy use outside the distribution stage, and it could take into account, for instance, whether water comes from a desalination plant or from a surface source. In other words, such an analysis would require accounting for the water energy footprints corresponding to all other stages previous to distribution (from abstraction to bulk transport).

Finally, $I_{5}$ shows the excess of energy delivered to users, that is, the surplus of energy delivered on top of the minimum energy required to meet the pressure standards. The value of this 
indicator can be improved by means of regulation elements such as valves or variable-speed pumps.

This performance assessment system is a useful tool to determine the optimal strategies to improve the energy management of the system. The indicators are also useful for assessing the potential for improvement.

\section{CONCLUSIONS}

Until a decade ago, the most relevant aspect of the water-energy relationship was hydroelectric production. Today, the focus has shifted towards water as an energy-consuming agent. This new perspective has turned water distribution into a very relevant stage and has brought attention not only on how much energy is consumed but also on how that energy is used. A proper assessment of how much energy is wasted as a result of network leakage is the main aim of this paper. Such energy loss results not only from the energy leaving the system through leaks (which can be quite significant depending on the energy footprint of the produced water, e.g., desalinated water) but also the energy needed to overcome additional friction losses created by higher circulating flow rates through the pipes.

The audit presented in this work can be used to identify the end uses of the energy entering the network and thus to define a performance assessment system that characterizes the network from an energy perspective through context information items and evaluates its energetic performance. The energy audit approach can also be supplemented with water and energy price information, as well as estimates of carbon and GHG impacts for the sources and amounts of energy use, in order to form part of a more holistic evaluation of system performance improvement options, such as might be undertaken in a cost-benefit analysis framework. As a 
matter of fact, these tools could easily be used from a regulatory or administrative perspective to create incentives for a more efficient use of energy in water distribution. The energy audit, like associated indicators, requires a previous water audit and that both of them are applied in similar conditions (either to the whole network or a sector). The energy audit can be extended to any period of time, but as the water balance is usually available for a year, the audit should cover the same period.

The energy audit is carried out with a simple but lengthy calculation process, manipulating EPANET result files. The software is not able by itself to calculate the suggested indicators. Should EPANET incorporate this option, the energy audit of the system would become an instant tool available for all technical network managers.

\section{ACKNOWLEDGEMENTS}

The authors would like to acknowledge the valuable contributions of the reviewers of this paper, as their comments and suggestions have helped to significantly improve its contents. The authors would also like to thank the Spanish Ministry of Science and Innovation for its support through the research project CGL2008-01910/BTE. 


\section{NotATION}

$A_{i}$ Section of the $\mathrm{i}$ tank

$C_{E, i}$ Emitter coefficient at node i.

$C_{p}$ Specific heat of water

$C_{1}$ Energy nature coming into the system

$C_{2}$ Energy management complexity of the network (context information)

e Energy per mass unit

$E_{C_{i}}\left(t_{1}\right)$ Energy compensation of the tank $i$ at the initial time of a simulation

$E_{C_{i}}\left(t_{p}\right)$ Energy compensation of the tank $i$ at the final time of a simulation

$E_{\text {Dissipated }}\left(t_{p}\right)$ Energy losses due to friction for the simulation period

$E_{F}\left(t_{p}\right)$ Friction energy for the simulation period

$E_{F}^{\prime}\left(t_{p}\right)$ Friction energy in a leak-free network

$E_{\text {Input }}\left(t_{p}\right)$ Input energy for the simulation period

$E_{L}\left(t_{p}\right)$ Energy through leaks for the simulation period

$E_{\text {min,useful }}$ Minimum useful energy needed in a frictionless, leak-free network served with the minimum required pressure.

$E_{\text {min,flat }}$ Minimum theoretical energy needed in an ideal network, frictionless, leak-free and flat.

$E_{N}\left(t_{p}\right)$ Energy supplied by the reservoirs for the simulation period

$E_{\text {Output }}\left(t_{p}\right)$ Output energy for the simulation period

$E_{P}\left(t_{p}\right)$ Energy supplied by pumping stations for the simulation period

$E_{U}\left(t_{p}\right)$ Energy supplied to users for the simulation period

$\left(h_{\text {Min }}\right)_{i}$ Minimum required piezometric head at node $i$

$H_{i}\left(t_{k}\right)$ Piezometric head at node $\mathrm{i}$ at time interval $t_{k}$

$H_{N i}\left(t_{k}\right)$ Piezometric head at the reservoir $\mathrm{i}$ at time interval $t_{k}$ 
$H_{P i}\left(t_{k}\right)$ Piezometric head of the I pump at time interval $t_{k}$

$H_{N i}$ Piezometric head of water at reservoir, $H_{N i}=H_{N i}\left(t_{k}\right)$

$I_{1}-$ Excess of supplied energy (performance indicator)

$I_{2}-$ Network energy efficiency (performance indicator)

$I_{3}$ - Energy dissipated through friction (performance indicator)

$I_{4}$ - Leakage energy (performance indicator)

$I_{5}$ - Standards compliance (performance indicator)

$n$ Number of demand nodes of the network

$n_{C}$ Number of compensation tanks of the network

$n_{i}$ Number of time intervals $\left(t_{p}=n_{i} \cdot \Delta t\right)$

$n_{L}$ Number of pipes of the network

$n_{N}$ Number of reservoirs

$n_{P}$ Number of pumps

$P_{C}$ Power supplied by compensation tanks

$P_{F}$ Power required to overcome friction losses

$P_{L}$ Power lost through leaks

$P_{N}$ Power provided by reservoirs

$P_{0}$ Total power supplied

$P_{P}$ Power provided by pumps

$P_{U}$ Power delivered to users

$\frac{P_{i}\left(t_{k}\right)}{\gamma}$ Pressure at node $\mathrm{i}$ at time interval $t_{k}$

$\frac{P_{\text {Min }}}{\gamma}$ Minimum pressure required by standards at any node and any time

$q_{j}\left(t_{k}\right)$ Flow rate at line $j$ at time interval $t_{k}$

$q_{l i}\left(t_{k}\right)$ Leakage flow rate at node $\mathrm{i}$ at time interval $t_{k}$

$q_{l j}\left(t_{k}\right)$ Leakage flow rate at line $\mathrm{j}$ at time interval $t_{k}$ 
$q_{u i}\left(t_{k}\right)$ Consumed flow rate at node $\mathrm{i}$ at time interval $t_{k}$

$q_{u j}\left(t_{k}\right)$ Consumed flow rate at line $\mathrm{j}$ at time interval $t_{k}$

Q Heat exchange at the control volume

$Q_{N i}\left(t_{k}\right)$ Flow rate supplied by reservoir $\mathrm{i}$ at time interval $t_{k}$

$Q_{P i}\left(t_{k}\right)$ Flow rate supplied by pumping station $\mathrm{i}$ at time interval $t_{k}$

$t_{k}$ Time interval of the steady state simulation

$t_{p}$ Total time of simulation (long or short)

$t_{p, T}$ Short-term/ long-term time threshold (days)

$u$ Internal energy per mass unit

$\forall_{L}\left(t_{p}\right)$ Total leakage volume for the simulation period

$\forall_{N}\left(t_{p}\right)$ Total volume injected for the simulation period

$\forall_{U}\left(t_{p}\right)$ Total volume consumed by users for the simulation period

$\forall_{\mathrm{u}, \mathrm{i}}\left(\mathrm{t}_{\mathrm{p}}\right)$ Total demand of node $\mathrm{i}$ during the simulation period $t_{p}$

W Work Exchange at the control volume

$z_{i}$ Elevation of node $i$

$z_{i}\left(t_{1}\right)$ Water level in the compensation tank $\mathrm{i}$ at the initial time of a simulation

$z_{i}\left(t_{p}\right)$ Water level in the compensation tank $\mathrm{i}$ at the final time of a simulation

$\alpha$ Emitter exponent

$\gamma$ Specific weight of water

$\Delta E_{C}\left(t_{p}\right)$ Total variation of the energy compensation of the tanks (from $t_{1}$ to $\left.t_{p}\right) . \Delta E_{C}\left(t_{p}\right)=\Delta E_{\text {Compensation }}\left(t_{p}\right)$

$\Delta E_{C \max }$ Maximum compensation energy of the tank

$\Delta h_{j}\left(t_{k}\right)$ Friction losses in line $\mathrm{j}$ at time interval $t_{k}$

$\Delta p_{\min }$ Excess pressure minimum value (for all nodes and simulations) calculated as the minimum difference between the real pressure and the minimum required pressure.

$\Delta t$ Time interval of integration $\left(\Delta t=t_{k+1}-t_{k}\right)$

$\rho$ Density of water 


\section{REFERENCES}

Alegre H., Baptista J.M., Cabrera E. Jr., Cubillo F., Duarte P., Hirner H., Merkel W., Parena R., (2006). "Performance Indicators for Water Suplly Services", IWA Publishing.

Almandoz, J.; Cabrera E., Arregui, F., Cabrera Jr. E. and Cobacho R. (2005). "Leakage Assessment through Water Distribution Network Simulation”. Journal of Water resources Planning and Management, 131(6), 458-466.

Burch, J., and Christensen, C. (2007) "Towards Development of an Algorithm for Mains Water Temperature.” Proceedings of the 2007 ASES Annual Conference, Cleveland, OH.

CEC (California Energy Commission), (2005). "California's Water-Energy Relationship report". California

Colombo A.F. and Karney B.W. (2002). "Energy cost of leaky pipes: Toward comprehensive picture". Journal of water resources, planning and management, 128(6), 441-450.

Colombo A.F. and Karney B.W. (2005). "Impacts of leaks on Energy Consumption in Pumped Systems with storage". Journal of water resources, planning and management, 131(2). 146155.

Lingireddy, S. and Wood, J. (1998) "Improved operation of water distribution systems using variable-speed pumps”. Journal of Energy Engineering, 124 (3), 90-103. 
NRC (National Research Council), 2008 "Desalination a national perspective". NAP Press, Washington, D.C.

Pelli,T. and Hitz, H.U. (2000). "Energy Indicators and savings in water supply". Journal American Water Works Association, Vol92 (6), June 2000.55-62.

Rossman, L. A. (2000). EPANET 2: User's manual, U.S. Environmental Protection Agency, Cincinnati.

Todini E., 2000 "Looped water distribution networks design using a resilience index based heuristic apprach” Urban Water 2 (2000) pp 115-122.

USDE (United States Department of Energy), (2006). "Energy Demands on Water Resources. Report to congress on the interpendency of energy and Water".

White, F.M. (1974) "Viscous fluid flow". B.J. Clark and Michael Gardner eds, McGraw-Hill, New York. Chapter 3. Solutions of the Newtonian viscous-flow equations. 